\title{
EFSUMB recent publications
}

The Use of Handheld Ultrasound Devices An EFSUMB Position Paper from the EFSUMB Publications Committee author Michael Bachmann Nielsen

https://www.thieme-connect.com/products/ejournals/pdf/10.1055/a-07832303.pdf

What should I know about my smart hand-held ultrasound device?

A lot of different types of hand-held ultrasound devices are now entering the market.
ECMUS has prepared a short document about important facts to know before such a device may be used for clinical purpose or what should be considered before purchasing it. The PDF-document can be downloaded from the EFSUMB website http://www. efsumb.org/blog/archives/885

Recommendations and Information about regulatory aspects related to the use of hand-held ultrasound devices

THE EFSUMB GUIDELINES AND RECOMMENDATIONS FOR THE CLINICAL PRACTICE
OF ELASTOGRAPHY IN NON-HEPATIC APPLICATIONS: UPDATE 2018 (LONG VERSION) has been accepted for publication in Ultraschall in der Medizin/European Journal of Ultrasound

Please check the link from the EFSUMB website www.efsumb.org

\section{Future congresses}

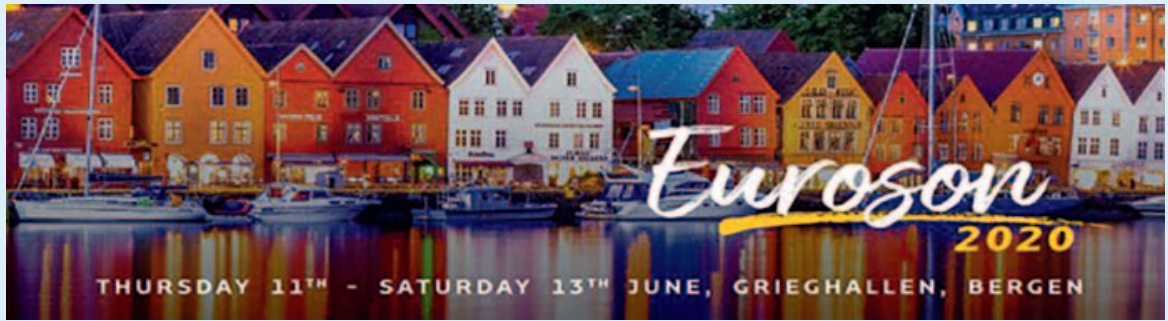

